\title{
Plant lectins and Toll-like receptors: implications for therapy of microbial infections
}

\author{
Luís C. N. da Silva and Maria T. S. Correia* \\ Departamento de Bioquímica, Universidade Federal de Pernambuco, Recife, Brazil \\ ${ }^{*}$ Correspondence: mtscorreia@gmail.com
}

Edited by:

James Stach, University of Newcastle, UK

Reviewed by:

Paul D. Brown, University of the West Indies, Jamaica

Rafael De Freitas E. Silva, University of Pernambuco, Brazil

Keywords: TLR receptors, immunomodulation, lectin, microorganisms, infection

Several plant lectins are known as potent immunomodulatory agents, and they are applied in different experimental models of infection (Afonso-Cardoso et al., 2011; Oliveira et al., 2013). Recent research has characterized these proteins as potential agonists of Toll-like receptors (TLRs or TLR), a family of mammalian homologs of Drosophila Toll protein involved in the detection of microbes and initiating inflammatory responses (O'Neill et al., 2013). In this opinion article, we highlighted some studies of plant lectins as modulators or agonists of TLRs in order to stimulate research interest in this fascinating area and promote knowledge sharing and scientific collaboration.

\section{A SHORT VIEW ON PLANT LECTINS}

Lectins are a very large class of carbohydrate-binding proteins of nonimmune origin. Through the interaction with sugars, they trigger several important cellular processes. Lectins are universally expressed and have been shown to function in animals, plants, and microorganisms as cell and molecular recognition proteins. However, the carbohydratebinding domains have been studied most intensively within the plant kingdom (Sharon, 2007; Vandenborre et al., 2011).

The discovery of plant lectins occurred in the 19th century, however, many questions about the biological role of these molecules remain obscure. Lectins may be involved in sugar transport, carbohydrate storage and they are associated as molecular chaperones (Van Damme et al., 2004; Liu and Li, 2013). The adhesion and agglutination properties of lectins have been related in the interaction of both symbiotic and pathogenic interaction of some microorganisms and host (Audfray et al., 2012). Plant lectins represent a group of proteins with obvious differences in their biochemical/physicochemical properties, molecular structure, carbohydratebinding specificity and biological activities (Liu et al., 2010). Lectins are oligomeric which exhibit a large structural diversity and the molecular size range from 60 to $400 \mathrm{kDa}$. Each lectin polypeptide contains many molecular domains, one of which is the non-catalytic carbohydrate recognition domain, responsible for their ability to recognize and interact with specific glycoconjugates, without altering their structure. In the past few years, hundreds of plant lectins have been purified and characterized in details with respect to their biochemical properties, carbohydrate-binding specificities, these approaches allowed their classification (Van Dammes et al., 2011).

\section{TOLL-LIKE RECEPTORS}

Plant materials represent an excellent source of immune modulators, which have been appointed as a new approach for combating infections caused by resistant microorganisms (Hancock et al., 2012). In this sense, a range of potential compounds have been proposed as agonists or inductors of immune receptors, including TLRs.

The TLR family is the best characterized group of innate immune receptors in terms of known ligands, downstream signaling pathways and functional relevance. They comprise a family of receptors homologous to Toll receptor from Drosophila melanogaster. In humans, the
TLR family includes 10 transmembrane proteins that play a crucial role in host defense: they recognize molecular characteristics of microorganisms, known as pathogen-associated molecular patterns (PAMPs) highly conserved between different classes of microorganisms. For example, TLR4 and accessory proteins recognize lipopolysaccharide (LPS), while TLR2 recognizes lipoteichoic acid and various lipopeptides (when in complex with either TLR-1 or TLR-6), and TLR5 recognizes flagellin (Hancock et al., 2012; O'Neill et al., 2013). In this way, TLR receptors represent important therapeutic targets for developing new drugs able to directly modulate the host response against microbial infection. In fact, some TLR agonists and TLR modulators have been investigated as potential drugs on clinical trials and research programmes (Hennessy et al., 2010; Murgueitio et al., 2012).

\section{PLANT LECTINS AND TOLL-LIKE RECEPTORS}

Lectins have been extensively used as valuable tools in the biomedical research. The versatility of these biomolecules is due to their interactions with receptor-linked glycans on cell surfaces, which may trigger cell signaling and physiological responses (Lam and Ng, 2011). Plant lectins are characterized as immunomodulator agent, which result in the production of certain cytokines and reactive species and induce efficient immune responses against tumors or microbial infections. A very comprehensive review of immunomodulatory lectins has recently been published by Souza et al. (2013). In order to 
investigate the mechanism of this action, some researchers correlated the activation of immune cells by lectins with the expression of TLR receptors.

Sodhi et al. (2007) investigated the expression of different TLRs induced by the famous lectin from Concanavalin A (Con A) using mouse macrophages as a model. Con A enhanced in vitro expression of TLRs (2-9) and its action was related with JNK, p38, p42/44, and NF-кB. The authors also showed the heterodimerization of TLR-2 and TLR-6. Additionally, Con A pre-treated-macrophages were more susceptible to induction of proinflammatory cytokines and nitric oxide by different TLR ligands (ZymosanA, PolyI:C, LPS, CpG DNA).

In other study, the Korean mistletoe lectin (KML-C) from Viscum album coloratum was shown to be a potent activator of TLR-4. The treatment of mouse peritoneal macrophages with KML-C-induced the upregulation of interleukin-1 receptorassociated kinase-1 (IRAK1) resulting in macrophage activation and TNF- $\alpha$ production, which was not observed when TLR-4 was blocked using a TLR-4-specific neutralizing antibody or TLR-4-deficient macrophages. The expression of TLR-4 was also induced by lectin-like protein from Anoectochilus formosanus (IPAF), resulting in the stimulation of TNF- $\alpha$ and IL-1 $\beta$, CD86, and MHC II and phagocytic activity (Park et al., 2010).

The capacity to modulate the TLR were explored to combat the experimental infection of Paracoccidiodes brasiliensis using native and recombinant $\mathrm{KM}^{+}$, a mannose-binding lectin from Artocarpus integrifolia. BALB/c mice were infected with $P$. brasiliensis and after 10 days both proteins were separately administered. $\mathrm{KM}^{+}$treatment reduced significantly colony-forming unit and induced higher levels of nitric oxide, INF- $\alpha$, TNF$\alpha$, and IL-12, which was dependent on TLR-2 (Coltri et al., 2008).

Recently, in a remarkable paper, phytohaemagglutinin (PHA from Phaseolus vulgaris) and its isoforms were showed as a specific human TLR-4 agonist during an initial screening. This result encouraged the authors to examine the effects of this and other lectins on external $(-2 / 6$, -4 , and -5$)$ and internal $(-3,-7,-8$, and -9) human TLRs. In this research, SBA
(Soybean agglutinin from Glycine max), PNA (peanut agglutinin from Arachis hypogaea), ConA and PHA only stimulated extracellular TLRs $(-2 / 6,-4$, or -5$)$ : TLR-4 for SBA and PNA; TLR-2/6 for ConA; TLR-2/6, -4 and for PHA-L. In other hand, WGA (wheat germ agglutinin from Triticum vulgaris) was the most promiscuous lectin activating all tested receptors, except TLR-3 and -4 . The jacalin (from Artocarpus integrifolia) was inactive. This variety of TLR agonist pharmacology is related to different sugar ligand specificity of each plant lectins, suggesting that the action is encoded by the carbohydrate recognition motifs on different TLRs (Unitt and Hornigold, 2011). TLR agonists have been proposed as adjuvants for vaccines against virus (Behzad et al., 2012; Hong et al., 2012), bacteria (Hancock et al., 2012), parasite (Moon et al., 2012) and fungi (LeibundGut-Landmann et al., 2012).

In conclusion, these observations encourage further studies for the characterization of plant lectins as novel agonists and modulators of TLR receptors. These proteins act by increasing the immune response of the host against microbial infections, thus overcoming their immunosuppressive mechanisms and offers an alternative to combat the increasing drug resistance. These approaches may also provide new insights on TLR biology and aid in the discovery of new targets glycosides useful in therapy.

\section{ACKNOWLEDGMENTS}

The authors express their gratitude to the Conselho Nacional de Desenvolvimento Científico e Tecnológico ( $\mathrm{CNPq})$, to the Coordenação de Aperfeiçoamento de Pessoal de Nível Superior (CAPES), and to the Fundação de Amparo à Ciência e Tecnologia do Estado de Pernambuco (FACEPE) for research Grants.

\section{REFERENCES}

Afonso-Cardoso, S. R., Silva, C. V., Ferreira, M. S., and Souza, M. A. (2011). Effect of the Synadenium carinatum latex lectin (ScLL) on Leishmania amazonensis infection in murine macrophages. Exp. Parasitol. 128, 61-67. doi: 10.1016/j.exppara.2011.02.006

Audfray, A., Claudinon, J., Abounit, S., RuvoënClouet, N., Larson, G., Smith, D. F., et al. (2012). Fucose-binding lectin from opportunistic pathogen Burkholderia ambifaria binds to both plant and human oligosaccharidic epitopes. J. Biol. Chem. 287, 4335-4247. doi: 10.1074/jbc.M111.314831

Behzad, H., Huckriede, A. L., Haynes, L., Gentleman, B., Coyle, K., Wilschut, J. C., et al. (2012) GLA-SE, a synthetic toll-like receptor 4 agonist, enhances T-cell responses to influenza vaccine in older adults. J. Infect. Dis. 205, 466-473. doi: 10.1093/infdis/jir769

Coltri, K. C., Oliveira, L. L., Pinzan, C. F., Vendruscolo, P. E., Martinez, R., Goldman, M. H., et al. (2008). Therapeutic administration of $\mathrm{KM}^{+}$lectin protects mice against Paracoccidioides brasiliensis infection via interleukin-12 production in a toll-like receptor 2-dependent mechanism. Am. J. Pathol. 173, 423-432. doi: 10.2353/ajpath.2008.080126

Hancock, R. E., Nijnik, A., and Philpott, D. J. (2012). Modulating immunity as a therapy for bacterial infections. Nat. Rev. Microbiol. 10, 243-254. doi: 10.1038/nrmicro2745

Hennessy, E. J., Parker, A. E., and O'Neill, L. A. (2010). Targeting Toll-like receptors: emerging therapeutics? Nature Rev. Drug Discov. 9, 293-307. doi: $10.1038 / \mathrm{nrd} 3203$

Hong, B, Lee, S.-H, Song, X.-T, Jones, L, Machida, K., Huang, X. F., et al. (2012). A super TLR agonist to improve efficacy of dendritic cell vaccine in induction of anti-HCV immunity. PLoS ONE. 7:e48614. doi: 10.1371/journal.pone.0048614

Lam, S. K., and Ng, T. B. (2011). Lectins: production and practical applications. Appl. microbiol. biotechnol. 89, 45-55. doi: 10.1007/s00253-0102892-9

LeibundGut-Landmann, S., Wüthrich, M., and Hohl, T. M. (2012). Immunity to fungi. Cur. Opin. Immunol. 24, 449-458. doi: 10.1016/j.coi.2012.04.007

Liu, B., Bian, H. J., and Bao, J. K. (2010). Plant lectins: potential antineoplastic drugs from bench to clinic. Cancer Lett. 287, 1-12. doi: 10.1016/j.canlet.2009.05.013

Liu, Y., and Li, J. (2013). An in vivo investigation of amino acid residues critical for the lectin function of arabidopsis calreticulin 3. Mol. Plant. 6, 985-987. doi: 10.1093/mp/sss 163

Moon, J. J., Suh, H., Li, A. V., Ockenhouse, C. F., Yadava, A., and Irvine, D. J. (2012). Enhancing humoral responses to a malaria antigen with nanoparticle vaccines that expand Tfh cells and promote germinal center induction. PNAS 109, 1080-1085. doi: 10.1073/pnas.1112648109

Murgueitio, M. S., Santos-Sierra, S., and Wolber, G. (2012). Discovery of novel TLR modulators by molecular modeling and virtual screening. J. Cheminforma. 4, 1. doi: 10.1186/1758-2946-4S1-P58

Oliveira, P. S., Rego, M. J., da Silva, R. R., Cavalcanti, M. B., Galdino, S. L., Correia, M. T., et al. (2013). Cratylia mollis 1, 4 Lectin: a new biotechnological tool in IL-6, IL-17A, IL-22, and IL23 induction and generation of immunological memory. Biomed Res. Int. 2013:263968. doi: $10.1155 / 2013 / 263968$

O’Neill, L. A., Golenbock, D., and Bowie, A. G. (2013). The history of Toll-like receptors-redefining innate immunity. Nat. Rev. Immunol. 13, 453-460. doi: $10.1038 /$ nri3446

Park, H. J., Hong, J. H., Kwon, H. J., Kim, Y., Lee, K. H., Kim, J. B., et al. (2010). 
TLR4-mediated activation of mouse macrophages by Korean mistletoe lectin-C (KML-C). Biochem. Biophys. Res. Commun. 396, 721-725. doi: 10.1016/j.bbrc.2010.04.169

Sharon, N. (2007). Lectins: carbohydratespecific reagents and biological recognition molecules. J. Biol. Chem. 282, 2753-2764. doi: 10.1074/JBC.X600004200

Sodhi, A., Tarang, S., and Kesherwani, V. (2007). Concanavalin A induced expression of Tolllike receptors in murine peritoneal macrophages in vitro. Inter. immunopharmacol. 7, 454-463. doi: 10.1016/j.intimp.2006.11.014

Souza, M. A., Carvalho, F. C., Ruas, L. P., RicciAzevedo, R., and Roque-Barreira, M. C. (2013). The immunomodulatory effect of plant lectins: a review with emphasis on ArtinM properties. Glycoconjugate J. 30, 641-657. doi: 10.1007/s10719-012-9464-4

Unitt, J., and Hornigold, D. (2011). Plant lectins are novel Toll-like receptor agonists.
Biochem. Pharmacol. 81, 1324-1328. doi: 10.1016/j.bcp.2011.03.010

Van Damme, E. J., Barre, A., Rougé, P., and Peumans, W. J. (2004). Cytoplasmic/nuclear plant lectins: a new story. Trends Plant Sci. 9, 484-489. doi: 10.1016/j.tplants.2004.08.003

Van Dammes, E. J., Fouquaert, E., Lannoo, N., Vandenborre, G., Schouppe, D., and Peumans, W. J. (2011). "Novel concepts about the role of lectins in the plant cell," in The Molecular Immunology of Complex Carbohydrates-3, ed A. M. Wu (New York, NY: Springer), 271-294. doi: 10.1007/978-1-44197877-6_13

Vandenborre, G., Smagghe, G., and Van Damme, E. J. (2011). Plant lectins as defense proteins against phytophagous insects. Phytochemistry 72, 1538-1550. doi: 10.1016/j.phytochem.2011.02.024

Conflict of Interest Statement: The Editor and Authors declare that while the authors and reviewer (Rafael E Silva) are affiliated with the same institution there has been no conflict of interest during the review and handling of this manuscript.

Received: 08 October 2013; accepted: 13 January 2014; published online: 03 February 2014.

Citation: da Silva LCN and Correia MTS (2014) Plant

lectins and Toll-like receptors: implications for therapy of microbial infections. Front. Microbiol. 5:20. doi: 10.3389/fmicb.2014.00020

This article was submitted to Antimicrobials, Resistance and Chemotherapy, a section of the journal Frontiers in Microbiology.

Copyright (C) 2014 da Silva and Correia. This is an open-access article distributed under the terms of the Creative Commons Attribution License (CC BY). The use, distribution or reproduction in other forums is permitted, provided the original author(s) or licensor are credited and that the original publication in this journal is cited, in accordance with accepted academic practice. No use, distribution or reproduction is permitted which does not comply with these terms. 